\title{
PERSONALITY PROFILE AMONG DIFFERENT BLOOD GROUPS
}

\author{
Sivaraman $S^{1}$, Vijay $B^{2}$, Ismail M33, Thirumalaikolundu Subramanian $P^{4}$
}

${ }_{1}^{1}$ Associate Professor, Department of Psychiatry, Trichy SRM Medical College Hospital and Research Centre, Affiliated to the Tamilnadu Dr. MGR Medical University, Irungalur, Trichy, Tamilnadu, India.

${ }^{2}$ CRRI, MBBS, Trichy SRM Medical College Hospital and Research Centre, Affiliated to the Tamilnadu Dr. MGR Medical University, Irungalur, Trichy, Tamilnadu, India.

${ }^{3}$ Research Co-ordinator, Trichy SRM Medical College Hospital and Research Centre, Affiliated to the Tamilnadu Dr. MGR Medical University, Irungalur, Trichy, Tamilnadu, India.

${ }^{4}$ Professor, Department of Medicine, Trichy SRM Medical College Hospital and Research Centre, Affiliated to the Tamilnadu Dr. MGR Medical University, Irungalur, Trichy, Tamilnadu, India.

ABSTRACT

\section{BACKGROUND}

Psychology of an individual varies due to internal and external factors. It has been proven that certain types of cancers are more prevalent among particular type of blood groups. Studies are carried out in different parts of the world to find out if relationship exists between blood groups and different behavioural patterns among humans.

The objective of this study is to find out whether the behavioural pattern differs among different blood groups.

\section{MATERIALS AND METHODS}

A standard Eysenck's questionnaire was used for this study. This questionnaire facilitates in identifying the liars and to exclude them from the study. About 500 samples were collected from medical students and their blood group details were obtained and recorded. All the data was analysed and interpreted.

\section{RESULTS}

The introvert behaviour was almost same in $\mathrm{A}, \mathrm{B}$ and $\mathrm{O}$ blood groups. The introvert behaviour in $\mathrm{AB}$ blood group differs significantly from that of $A, B$ and 0 blood groups. The extrovert behaviour within $A B$ and 0 differ significantly, [p=0.015]. Likewise, the Neuroticism between $A B$ to $A$ and B blood groups significantly varied $[p<0.05]$.

\section{CONCLUSION}

When the extrovert and average behaviour of all the four blood groups were analysed, this behaviour was not found to be statistically significant in all blood groups. Besides the introvert behaviour was found to be statistically significant, the neuroticism behaviour was analysed among blood groups, the difference was found to be statistically significant.

\section{KEY WORDS}

Eysenck's Questionnaire, Lie Score, Introvert, Extrovert, Neuroticism.

HOW TO CITE THIS ARTICLE: Sivaraman S, Vijay B, Ismail M, et al. Personality profile among different blood groups. J. Evolution Med. Dent. Sci. 2018;7(28):3166-3169, DOI: 10.14260/jemds/2018/712

\section{BACKGROUND}

Human individuals differ in terms of blood group, which gives a unique identity to them. Till now about 33 blood group systems are identified (ABO, Rh, MNS, Kell, Lewis...).(1) Among these the major blood group system is $A B O$ system and $\mathrm{Rh}$ system. Blood group types in the ABO system are $\mathrm{A}, \mathrm{B}, \mathrm{AB}$ and O.(2) Also, behavioural pattern differs in different individuals in humans and give a unique identity to them. Behaviour is defined as the capacity of mental, physical and emotional and social activities experienced during the human beings lifetime. Human behaviour is dictated by different factors such as genetics, social norms, core faith, attitude and other

'Financial or Other Competing Interest': None.

Submission 30-05-2018, Peer Review 23-06-2018,

Acceptance 30-06-2018, Published 09-07-2018.

Corresponding Author:

Dr. Sivaraman $S$,

Associate Professor

Department of Psychiatry,

Trichy SRM Medical College Hospital and Research Centre,

Affiliated to the Tamilnadu Dr. MGR Medical University,

Irungalur, Trichy, Tamilnadu, India.

E-mail: sivaramanaiims@gmail.com

DOI: $10.14260 /$ jemds $/ 2018 / 712$

\section{(c) $(1)$}

factors.(3) Studies are going in various parts of the world to understand the relationship between human behavioural pattern and blood groups. In some countries, especially in Japan there was widespread findings that blood type is strongly linked to personality.(4) A study on "obsessional personality traits and ABO blood types" found greater incidence of obsessional (Compulsive) personality traits in blood types A, B and AB than in type 0.(5) In India, study on "possible relationship of blood types to certain personality variables" shows that type $B$ individuals to have higher neuroticism (Anxious) scores (compared to types $\mathrm{O}$ and A).(6) In duodenal ulcer patients Neumann, Shoaf, Harvill, Jones and Edward have reported that type A individuals had higher trait of anger, anxiety and depression compared to type 0 individuals on standard measures of personality.(7) In contrast, some studies show that there is no relationship between behaviour and blood group.(8) Hence, this study was undertaken to find out a relationship between blood groups and behavioural patterns among humans.

\section{Objective}

The objective of this study is to find out whether the behavioural pattern differs among different blood groups. 


\section{MATERIALS AND METHODS}

This study was taken up in a tertiary teaching hospital. The study was conducted in 2015 between May and August. The study subjects were medical students. A standardised questionnaire formulated by Eysenck's was used to collect data from the study subjects. ${ }^{(9)}$ The Eysenck's questionnaire contains 57 questions of which 9 questions were related to lie score, 24 questionnaire connected to study extraversion behaviour and 24 questions related to find out the Neuroticism behaviour.(10) The design of the study was a cross-sectional observational study conducted at the Department of Psychiatry of a tertiary care teaching hospital. Prior to the study, the study proposal was presented before the Institutional Ethics Committee and ethical clearance certificate was obtained. Informed consent was obtained from all the participants after explaining the study and explaining doubts. Strict confidentiality was maintained throughout the study period. 500 students of the age group of 17 - 29 studying Ist year to CRRIs were selected for this study. Blood group identification done during admission and entered in the respective identification card was taken as the source for individual blood group for this study. Eysenck Personality Questionnaire was distributed and asked them to answer the questions. Out of 500 participants, only 467 responded. Results calculated from the remaining 250 samples after deducting individuals were having lie score 5 and above.

Among the responded participants, only 250 samples were selected for further analysis of Extraversion, Introversion and Neuroticism based on the lie score.(9) The extraversion individuals exhibits behaviour of outgoing, talkative, high on positive affect (feeling good) and in need of external stimulation. (9) Whereas the introversion individual's behaviour will be chronically over aroused and are therefore in need of peace and quiet to bring them up to an optimal level of performance $\left.{ }^{9}\right)$ and Neuroticism characterised by high levels of negative affect such as depression and anxiety.(9)

After receiving the questionnaire, the data were analysed and based on Eysenck's classification. The score 18 and above was considered as Extraversion behaviour; 17 to 11 was considered as average in Extraversion/ Introversion dimension. Score 10 and below was taken as introvert behaviour. Scores 17 and above was taken as neurotic. Scores between 9 and 16 were considered average in Neuroticism/stable dimension. Scores 10 and below were accounted as stable. In the Neuroticism question section score 14 and above was considered as neurotics; 4 and below was considered as emotionally well-balanced and scores between 5 and 13 taken as normal.(11) Further the data were analysed for the pattern of behaviour among different blood groups, gender pattern, geographical origin and socioeconomic status.

\section{Inclusion Criteria}

The samples secured lie score between below 5 were included in this study as per the criteria of Eysenck's questionnaire.

\section{Exclusion Criteria}

The students those who secured the lie score between 5 and above were excluded from this study due to lie behaviour as per Eysenck's questionnaire.

\section{Statistical Analysis}

The answers were entered in the Vassarstats.net and Fisher's exact probability test $2 \times 4$ and Chi-square tests were done to elicit the variance within the blood groups and between the blood groups to find out the statistical significance.

\section{RESULTS}

\begin{tabular}{|c|c|c|c|}
\hline Sl. No. & Variables & Frequency & Percentage \\
\hline \multicolumn{4}{|c|}{ Gender } \\
\hline 1 & Male & 125 & 50 \\
\hline 2 & Female & 125 & 50 \\
\hline \multicolumn{4}{|c|}{ Geographical Category } \\
\hline 3 & Urban & 62 & 24.8 \\
\hline 4 & S. Urban & 63 & 25.2 \\
\hline 5 & Rural & 125 & 50 \\
\hline \multicolumn{4}{|c|}{ Economic Status } \\
\hline 6 & Low Income & 153 & 61.2 \\
\hline 7 & Middle Income & 74 & 29.6 \\
\hline 8 & High Income & 23 & 9.2 \\
\hline \multicolumn{4}{|c|}{ Table 1. Sociodemographic Profile } \\
\hline
\end{tabular}

The study subjects consist of male and female having equal proportion of $50 \%$ each. Similarly, the geographical area of study population was also almost same in urban and rural areas. The poor income group consists of $61.2 \%$, middle income group comprised of $29.2 \%$ and participation of high income group was only $9.2 \%$ [Table-1].

\begin{tabular}{|c|c|c|c|}
\hline Sl. No. & Blood Group & Frequency & Percentage \\
\hline 1 & $\mathrm{~A}$ & 58 & 23.2 \\
\hline 2 & $\mathrm{~B}$ & 79 & 31.6 \\
\hline 3 & $\mathrm{AB}$ & 17 & 6.8 \\
\hline 4 & 0 & 96 & 38.4 \\
\hline Total & \multicolumn{3}{|c|}{ Table 2. Blood Group Profile } \\
\hline
\end{tabular}

In this study the A group accounts for $22.8 \%$, blood group ' $\mathrm{B}$ ' constitute for 31.6 and ' $O$ ' group comprised of $38.4 \%$, but the representation of 'AB' group was only $68 \%$ [Table-2].

\begin{tabular}{|c|c|c|c|}
\hline $\begin{array}{c}\text { Sl. } \\
\text { No. }\end{array}$ & $\begin{array}{c}\text { Extroversion/Introversion } \\
\text { Dimension n=250 }\end{array}$ & Frequency & $\mathbf{\%}$ \\
\hline 1 & Extrovert & 22 & 8.8 \\
\hline 2 & Average & 208 & 83.2 \\
\hline 3 & Introvert & 20 & 8 \\
\hline & $\begin{array}{c}\text { Neuroticism/ Stable } \\
\text { Dimension n=250 }\end{array}$ & $\%$ \\
\hline 1 & Stable & 122 & 49 \\
\hline 2 & Average & 122 & 49 \\
\hline 3 & \multicolumn{3}{|c|}{ Neuroticism } \\
\hline \multicolumn{2}{|c|}{ Table 3. Personality Profile } \\
\hline
\end{tabular}


Among all the blood groups, extrovert and introvert was represented by $8.8 \%$ and $8 \%$ respectively and average accounted for $83.2 \%$. Regarding neuroticism and stable behaviour, the neuroticism was found only in $2 \%$ and stable and average behaviour accounted for $49 \%$ each respectively [Table-3].

\begin{tabular}{|c|c|c|c|c|c|}
\hline $\begin{array}{r}\text { Sl. } \\
\text { No. }\end{array}$ & $\begin{array}{c}\text { Extroversion/Introversion } \\
\text { Dimension n=250 }\end{array}$ & \multicolumn{4}{|c|}{ Blood Groups \% } \\
\hline & & A & B & AB & 0 \\
\hline 1 & Extrovert & 10 & 8 & 18 & 6 \\
\hline 2 & Average & 81 & 83 & 82 & 85 \\
\hline 3 & Introvert & 9 & 9 & 0 & 9 \\
\hline
\end{tabular}

Table 4. Extroversion/Introversion Dimension among different Blood Groups

When the extrovert and average behaviour of all the four blood groups were analysed, this behaviour was not found to be statistically significant in all blood groups $p<0.5[p=0.316$, $\mathrm{p}=0.726$ respectively]. Besides the introvert behaviour was found to be statistically significant $\mathrm{p}<0.05[\mathrm{p}=.0218]$ [Table-4].

When analysed the personality profile between different blood groups viz. A with $\mathrm{B}, \mathrm{AB}, \mathrm{O}$ for one blood group with other separately for extrovert, average and introvert it was found that $A B$ and $O$ blood group significantly varied in extrovert behaviour $[p=0.015]$ and other blood groups did not vary significantly. Likewise, the average behaviour also did not vary significantly. But the introvert behaviour between $A B$ and $O$ [p=0.015], $A$ and $A B$ [p=0.0001] $B$ and $A B$ $[\mathrm{p}=.0001]$ and $A B$ and $0[\mathrm{p}=.0032]$ vary significantly.

\begin{tabular}{|c|c|c|c|c|c|}
\hline $\begin{array}{c}\text { Sl. } \\
\text { No. }\end{array}$ & $\begin{array}{c}\text { Neuroticism/Stable } \\
\text { Dimension n=250 }\end{array}$ & \multicolumn{4}{|c|}{ Blood Groups \% } \\
\hline & & A & B & AB & 0 \\
\hline 1 & Neuroticism & 49 & 42 & 64 & 52 \\
\hline 2 & Average & 49 & 55 & 36 & 46 \\
\hline 3 & Stable & 2 & 3 & 0 & 2 \\
\hline \multicolumn{4}{|c|}{$\begin{array}{c}\text { Table 5. Personality Behaviour among different Blood } \\
\text { Groups }\end{array}$} \\
\hline
\end{tabular}

The neuroticism behaviour was analysed among blood groups. The difference was found to be statistically significant $\mathrm{p}<0.05[\mathrm{p}=.0175]$, whereas the average and stable behaviour were not statistically different, $p=0.05$ [Table-5].

When neuroticism behaviour was analysed between two blood groups, they did not vary significantly, except $A$ and $A B$ $[p=0.045]$ and $B$ and $A B$ [0.002]. Likewise, the average behaviour did not vary significantly within blood groups except $B$ and $A B$ [p=0.010]. Stable behaviour did not vary in any blood group pairs.

\section{DISCUSSION}

After eliminating lie score participants, the male and female was equal in participation. Interestingly, half of the participants from rural sector and low-income group accounted for $61.2 \%$ of participation. The prevalence of different blood groups concur with the study of Hariharan V et al at Coimbatore, Tamilnadu.(9) In the Extrovert and Introvert dimension Blood Group $\mathrm{A}$ and $\mathrm{AB}$ showed same pattern, whereas Blood Groups B and 0 showed almost similar pattern [Table-4]. But on the contrary A and B pattern was similar and $\mathrm{AB}$ and $\mathrm{O}$ pattern was almost similar
[Table-5]. Angst et al in their study showed that blood Group $\mathrm{AB}$ members were more introvert than $\mathrm{A}, \mathrm{B}$ and $\mathrm{O}$ blood groups,(12) which differs from our study. In our study $A B$ blood group were not at all introvert but $\mathrm{A}, \mathrm{B}$ and $\mathrm{O}$ were having almost equal introvertism. In a study titled "Blood Group and Personality," Mary Rogers et al predicted that blood Type B individuals would be higher on neuroticism, blood Type 0 individuals would be higher on extraversion and optimism, blood Type A individuals would be higher on agreeableness and blood Type $\mathrm{AB}$ individuals would be higher on conscientiousness.(13) In our findings $A B$ blood groups were more extravert than A, B and O. Amreen Nahida et al found out co-relation between personality and blood group and found blood Group $\mathrm{A}, \mathrm{AB}$ and $\mathrm{O}$ are possessing psychoticism nature and blood Group $B$ having extraversion nature, whereas $\mathrm{AB}$ blood groups were more extravert in this study.(14) Hasanain Sadiq Salih Abakh found out that blood Group A is devoid of depression.(15) In this study, $48.27 \%$ of A blood group were found to have Neuroticism. Nargesalizadeh et al have reported that there is significant and positive corelation between blood group and group participation. In that blood Group A has highest group participation, $\mathrm{O}$ has second highest group participation and $B$ has least group participation.(16) Mohammad Sharifi et al found five factors of neuroticism, extroversion, openness, agreeableness and consciousness among students. In that among five factors three factors such as neuroticism, agreeableness and consciousness has showed no relationship with blood type. Extroversion and openness are linked with different blood groups.(17) Mohammad Sharif et al found out significant difference between blood group and personality type TA2. In type TA2, personality was found more in 0 blood group than Blood Group A and AB.(18) However, Kengo Nawata conducted a large scale survey comprising of 10,000 people in Japan that reported no significant difference between blood type and personality.(19)

In our study introvert behaviour was almost similar among A, B and O blood group. On the contrary, introvert was not present in the $A B$ blood group. The difference among $A, B$ and $O$ blood group are not statistically significant. However, the difference in the extrovert behaviour of $\mathrm{AB}$ with $\mathrm{O}$ blood group was statistically significant. Likewise, neuroticism between $A B$ to $A$ and $A B$ to $B$ was found to be statistically significant. Gender wise introvert, extrovert and neuroticism behaviour were not significantly different. Likewise, there is no difference of introvert, extrovert and neuroticism among various geographic distribution. However, introvert behaviour was statistically significant in B blood group between annual income of 5 lakhs and 5 to 10 lakhs. Likewise, extrovert behaviour of $\mathrm{AB}$ blood group was statistically significant between annual income of below 5 lakhs and above 10 lakhs.

\section{CONCLUSION}

The extrovert, introvert and neurotic behaviour among different blood groups did not show significant difference among different blood groups in most of the cases. However, extrovert behaviour of $A B$ blood groups significantly differed with $O$ blood group and Neurotic behaviour of $A B$ differed with A and B blood groups. A large sample on communitybased study will reveal more information of behavioural difference among different blood groups. 


\section{Limitation}

This is a single-centred study with limited sample size.

\section{REFERENCES}

[1] Daniels G. Human blood groups. 3rd edn. Chicester, United Kingdom: Wiley-Blackwell 2013. ISBN: 9781444333244.

[2] Landsteiner K, Wiener AS. An agglutinable factor in human blood recognized by immune sera for rhesus blood. Proc Soc Exp Biol Med 1940;43:223-4.

[3] McConnel JV. Understanding human behaviour: an introduction to psychology. Oxford, England: Holt, Rinehart \& Winston Publishing Company, 1974. ISBN no: 0030710960, 3-10.

[4] Sullivan K. What's your type? (The title included the word "sign" before type, with sign crossed out. 2000 . Retrieved December 29, 2001, http://www.don8bld.org/trivia/sign.htm (Original work published January 14, 1995, in the Washington Post)

[5] Rinieris P, Stefanis C, Rabavilas A. Obsessional personality traits and $\mathrm{ABO}$ blood types. Neuropsychobiology 1980;6(3):128-31.

[6] Marutham P, Prakash IJ. A study of the possible relationship of blood types to certain personality variables. Indian Journal of Clinical Psychology 1990;17(2):79-81.

[7] Neumann JK, Shoaf FB, Harvill LM, et al. Personality traits and blood type in duodenal ulcer patients and healthy controls: Some preliminary results. Medical Psychotherapy: An International Journal 1992;5:83-8.

[8] Hasegawa $\mathrm{H}$. There is no ground for believing the blood-type theory of personality. Proceedings of the 27 th annual meeting of Japanese association of educational psychology. 1985: p. 422-3.

[9] Hariharan V, Arunkumar T, Aravazhi AN. A study of blood groups and their association with coronary artery disease risk factors and comparison of cardio metabolic profile of young adults among various districts in Kerala and Tamil Nadu. International Journal of Biomedical Research 2016;7(2):066-9.
[10] Eyesenck HJ, Eyesenck SBG. Manual of the Eysenck personality inventory. London: University of London Press 1964.

[11] Bisht VBS. Study of different dimensions of personality of Indian soccer referees. IJAR 2016;2(9):745-7.

[12] Angst J, Maurer-Groeli YA. Blood groups and personality. Archiv für Psychiatrie und Nervenkrankheiten 1974;218(4):291-300.

[13] Rogers M, Glendon AI. Blood type and personality. Personality and Individual Differences 2003;34(7):1099-112.

[14] Nahida A, Chatterjee N. A study on relationship between blood group and personality. IJHS 2016;2(1):239-43. ISSN: 2395-7476. (C) 2016 IJHS. www.homesciencejournal.com Received: 26-01-2016. Accepted: 27-02-2016, 239-245.

[15] Abakah HSS. Depression and its relation with blood group according differences (sex). International Journal of Applied Science and Technology 2015;5(1):175-85.

[16] Alizadeh N, Afshar H, Sohrabi F, et al. Personality psychological strategy in the management of productivity. International Journal of Research in Management 2013;2(3):16-41. ISSN 2249-5908.

[17] Sharifi M, Ahmadian H, Jalali A, et al. The relationship between the big five personality factors with blood types in Iranian university students. Journal of Chemical and Pharmaceutical Research 2015;7(5):233-40.

[18] Sharifi M, Ahmadian H, Jalili A. The relationship between blood groups and "type A" personality. Der Pharmacia Lettre 2015;7(9):35-9.

[19] Nawata K. No relationship between blood type and personality: evidence from large-scale surveys in Japan and the US. Shinrigaku Kenkyu: The Japanese Journal of Psychology 2014;85(2):148-56. 